\title{
Ion transfer across the water|trifluorotoluene interface
}

\author{
Astrid J. Olaya, Peiyu Ge, Hubert H. Girault* \\ Laboratoire d'Electrochimie Physique et Analytique, Station 6, Ecole Polytechnique Fédérale de Lausanne, CH-1015 Lausanne, Switzerland
}

\section{A R T I C L E I N F O}

\section{Article history:}

Received 15 February 2012

Received in revised form 7 March 2012

Accepted 8 March 2012

Available online 16 March 2012

\section{Keywords:}

Liquid|liquid interfaces

Trifluorotoluene

Charge transfer

\begin{abstract}
A B S T R A C T
This work introduces trifluorotoluene as an alternative organic solvent for studying charge transfer across liquid|liquid interfaces. In comparison with the most popular organic solvents in this field, 1,2-dichloroethane and nitrobenzene, trifluorotoluene is less toxic since it is not considered a carcinogen agent, and offers a larger potential window. When comparing the standard Gibbs energies of ion partition from water to trifluorotoluene with those reported at the water|1,2-dichloroethane and water|nitrobenzene interfaces, linear relationships were found, making easy to extrapolate the Gibbs energy of other ions from these empiric correlations. 1,2-dichloroethane and nitrobenzene can be efficiently replaced by trifluorotoluene for studying charge transfer at liquid|liquid interfaces.
\end{abstract}

(C) 2012 Elsevier B.V. All rights reserved.

\section{Introduction}

Even though 1,2-dichloroethane (DCE) [1-8] and nitrobenzene (NB) [9-12] are among the most popular solvents for studying charge transfer across liquid|liquid interfaces, they are classified as highly toxic solvents and carcinogen agents [13-18].

Other solvents such as 2-nitrophenyl octyl ether (NPOE), 2heptanone [19,20], 2-octanone [20], 1,6-dichlorohexane [21,22], 1,4dichlorobutane [22], acetophenone [23], dichlorobenzene [24], and even lately room temperature ionic liquids (RTIL) [25-29] have been found to be suitable, but are either expensive or difficult to prepare.

Trifluorotoluene (TFT) is a colourless and free-flowing liquid with a relatively low toxicity and price, considered as an efficient substitute for dichloromethane and similar solvents in organic synthesis [30,31]. It is not a carcinogen agent according to its MSDS safety data sheet. Comparing the physical properties of DCE and TFT, the dielectric constant and density of TFT $\left(9.2\right.$ at $20^{\circ} \mathrm{C}$ and $1.19 \mathrm{~g} / \mathrm{mL}$, respectively) are only slightly smaller than those of DCE $\left(10.3\right.$ at $20^{\circ} \mathrm{C}$ and $1.25 \mathrm{~g} / \mathrm{mL}$ ), whilst the boiling point of TFT $\left(102{ }^{\circ} \mathrm{C}\right)$ is $18{ }^{\circ} \mathrm{C}$ higher than that of DCE, suggesting that TFT could be a potential candidate to replace DCE in studies at liquid|liquid interfaces.

In this work, the standard transfer potential $\left(\Delta_{\mathrm{o}}^{\mathrm{w}} \phi^{0}\right)$ of different ions transferred across the water|TFT interface were determined and compared with those reported at the water|DCE and water|NB interfaces. The relationship between the standard Gibbs energies of the partition $\left(\Delta G_{\mathrm{tr}}^{0, \mathrm{w} \rightarrow \mathrm{o}}\right)$, when comparing the three interfaces is linear, making easy to extrapolate the Gibbs energy of other ions from such empiric correlations.

\footnotetext{
* Corresponding author. Tel.: + 4121693 3145; fax: +4121693 3667 E-mail address: hubert.girault@epfl.ch (H.H. Girault).
}

\section{Experimental}

\subsection{Chemicals and reagents}

All solvents and chemicals were used as received without further purification. Bis(triphenylphosphoranylidine)ammonium chloride (BACl 98\%), lithium tetrakis(pentafluorophenyl)-borate ethyl etherate (LiTB purum), tetramethylammonium chloride (TMACl 98\%), tetrabutylammonium bromide ( $\mathrm{TBABr} 99 \%$ ) and sodium tetraphenylborate (NaTPB, 99.5\%) were purchased from Fluka. $\alpha, \alpha, \alpha$-Trifluorotoluene (TFT 99\% +), tetraethylammonium chloride (TEACl 99\%) and tetrapropylammonium bromide (TPropABr 98\%) were purchased from Acros. Tetraphenylarsonium chloride monohydrate (TPAsCl 99\%) was purchased from ABCR. 1,2-Dichloroethane (DCE, grade HPLC) was purchased by Applichem. Tetraphenylarsonium tetraphenylborate (TPAsTPB) was prepared as reported in Ref. [33]. Bis(triphenylphosphoranylidine)ammonium tetrakis(pentafluorophenyl)-borate (BATB) was prepared as reported in Ref. [8]. All the aqueous solutions were prepared in ultra pure water $\left(18.2 \mathrm{M} \Omega \mathrm{cm}^{-1}\right)$. The solubility of TPAsTPB in TFT was found to be rather low, thus, in order to dissolve enough salt to see reliable transfer of ions, a saturated TPAsTPB solution was prepared, sonicated for $15 \mathrm{~min}$ and filtrated to remove the insoluble salt. Clear signals of the transfer of $\mathrm{TPAs}^{+}$and $\mathrm{TPB}^{-}$were observed by cyclic voltammetry.

\subsection{Ion transfer voltammetry measurements at the water|TFT interface}

Ion transfer voltammetry measurements at the water|TFT interface were performed in a four-electrode cell with two reference electrodes to polarise the interface and two platinum counter electrodes to provide the current. A commercial potentiostat (PGSTAT 30, Metrohm, $\mathrm{CH}$ ) was used. The external potential was applied by means of two silver/silver chloride $(\mathrm{Ag} / \mathrm{AgCl})$ reference electrodes, 
which were connected to the aqueous and the organic phases, respectively, by means of a Luggin capillary. The composition of the electrochemical cells is illustrated in Scheme 1. The origin of the Galvani potential difference $\Delta_{\mathrm{o}}^{\mathrm{w}} \phi$ was estimated by using the extrathermodynamic TATB assumption [32].

\section{Results and discussion}

Taking into account the standard transfer potential of the ions forming the supporting electrolytes in both phases (see cell I, Scheme $1 ; \mathrm{BA}^{+}, \mathrm{TB}^{-}, \mathrm{Li}^{+}$and $\mathrm{Cl}^{-}$), the cyclic voltammograms in Fig. 1 are limited by the transfer of $\mathrm{Li}^{+}$in the positive side of the scale and by $\mathrm{Cl}^{-}$at the negative part [8]. In spite of the low solubility of the electrolyte TPAsTPB in TFT, the $\Delta_{\mathrm{o}}^{\mathrm{w}} \phi_{1 / 2}$-scale was calibrated by using the extra-thermodynamic TATB assumption in which the standard Gibbs energy of partition of TPAsTPB can be split into two equal parts for the cation and the anion because the radii of both ions are very similar; $\Delta G_{\mathrm{tr}}^{0, \mathrm{w} \rightarrow \mathrm{o}} \quad\left(\mathrm{TPAs}^{+}\right)=\Delta G_{\mathrm{tr}}^{0, \mathrm{w} \rightarrow \mathrm{o}} \quad(\mathrm{TPB})$ or $\Delta_{\mathrm{o}}^{\mathrm{w}} \phi_{1 / 2}$ $\left(\mathrm{TPAs}^{+}\right)=-\Delta_{\mathrm{o}}^{\mathrm{w}} \phi_{1 / 2}\left(\mathrm{TPB}^{-}\right)$[32]. Thus, the zero of the $\Delta_{\mathrm{o}}^{\mathrm{w}} \phi_{1 / 2}$-scale is located in the middle of the half-wave potentials of both ions (Fig. 1a). TPropA ${ }^{+}$was added also to the aqueous phase (see cell II, Scheme 1) in order to determine its $\Delta_{\mathrm{o}}^{\mathrm{w}} \phi_{1 / 2}$, and use it as a secondary reference in forward voltammograms made at the water|TFT interface. Fig. 1a shows the calibrated voltammogram of the supporting electrolyte at the water|TFT and the water|DCE interfaces. The potential window obtained at the water|TFT interface is around $400 \mathrm{mV}$ and $100 \mathrm{mV}$ larger toward the positive and the negative side, respectively, than the potential window obtained at the water|DCE interface.

The usual analogous series of ammonium salts, $\mathrm{TMA}^{+}, \mathrm{TEA}^{+}$, $\mathrm{TPropA}^{+}$and $\mathrm{TBA}^{+}$, was studied at the water|TFT interface (cells IVVI, Scheme 1) in order to calibrate the whole potential window and determine if there is any important deviation with respect to the behaviour found at the water|DCE and water|NB interfaces for the same series (Fig. 1c). As expected from the behaviour observed in DCE the scan rate dependence of the transfer of TPropA ${ }^{+}$and $\mathrm{TMA}^{+}$ (see cell IV, Scheme 1) when tested from $10 \mathrm{mV} / \mathrm{s}$ to $50 \mathrm{mV} / \mathrm{s}$, showed that the process is controlled by diffusion. The same behaviour was found for the other cations. The calibration of the potential window was made systematically from TPropA ${ }^{+}$whose $\Delta_{\mathrm{o}}^{\mathrm{w}} \phi_{1 / 2}$ was already

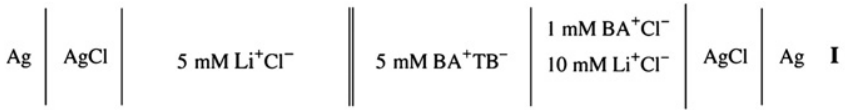

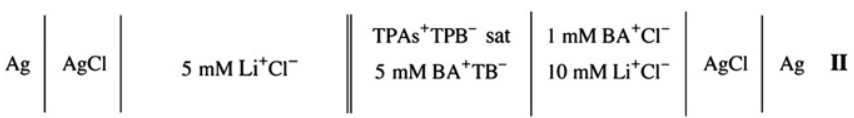

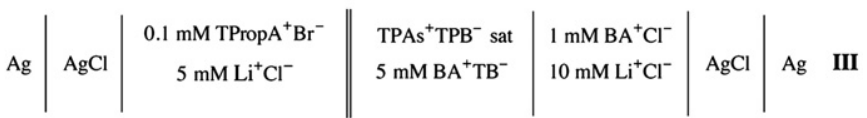

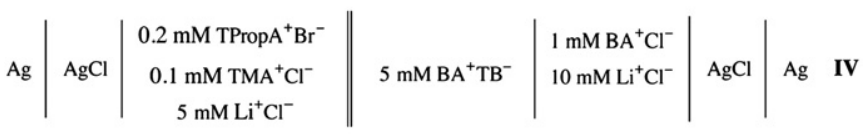

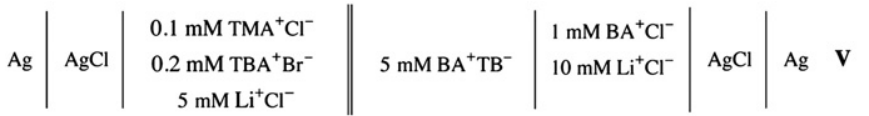

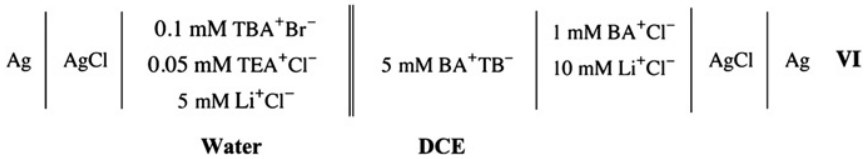

Scheme 1. Composition of the electrochemical cells for the ion transfer voltammetry studies.
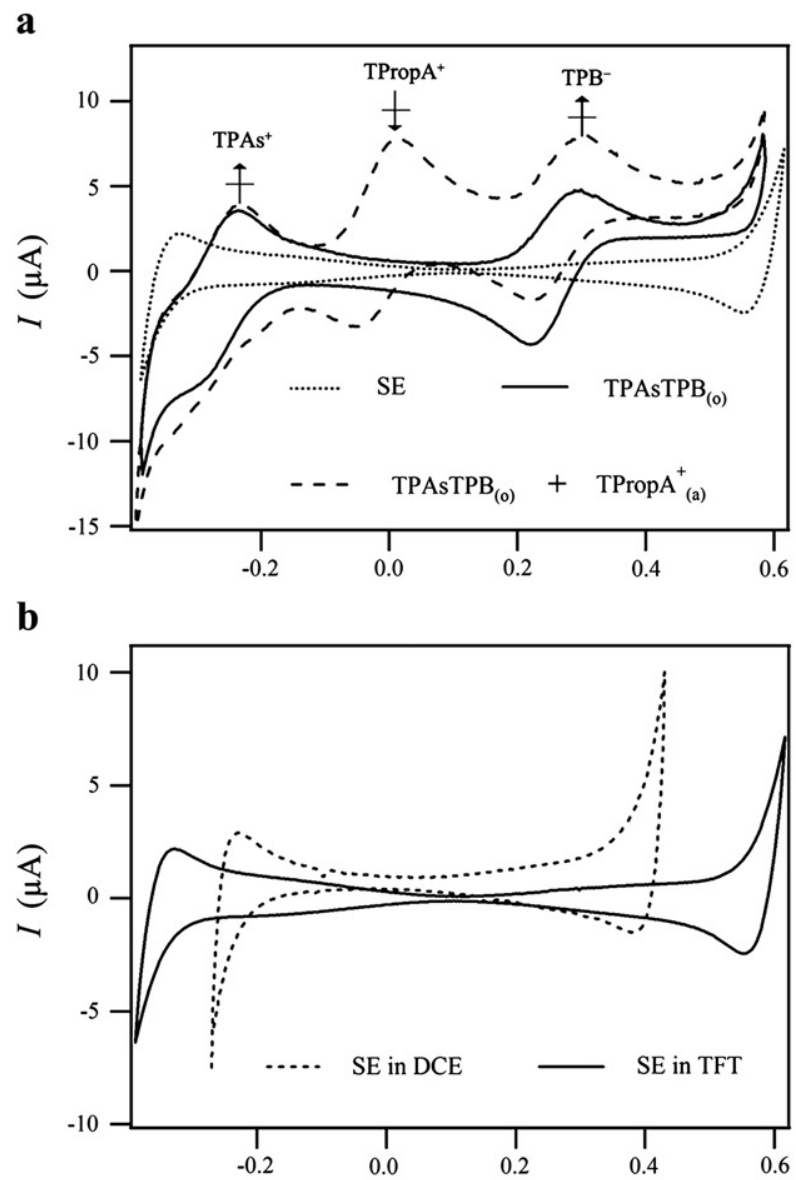

C

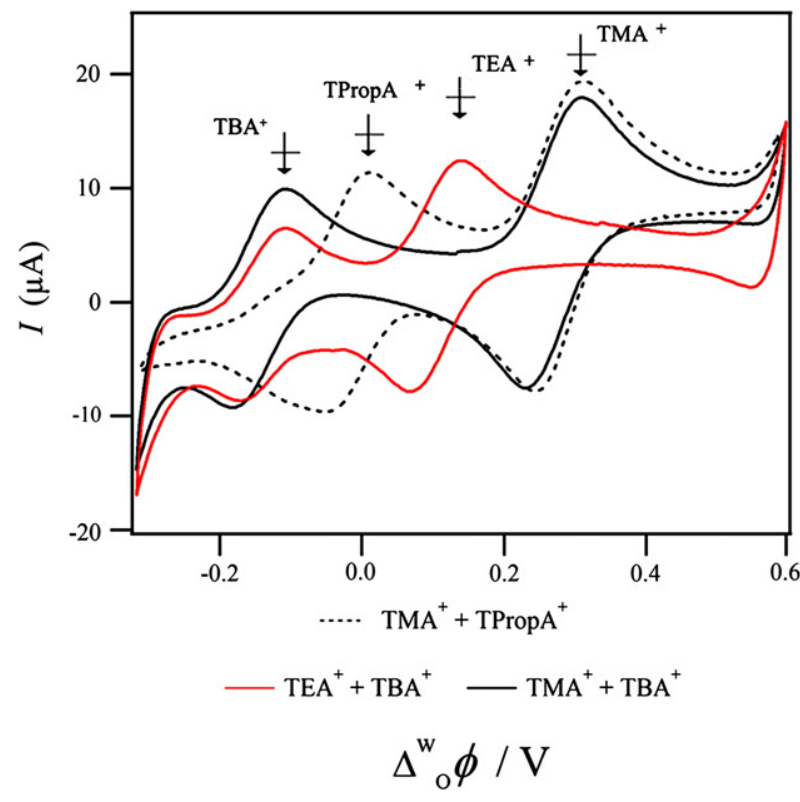

Fig. 1. (a) Calibration of the potential window at the water|TFT interface using the TATB assumption. Scan rate: $10 \mathrm{mV} / \mathrm{s}$, SE: Supporting Electrolyte. (b) Comparison of the potential windows obtained at the water|TFT and water|DCE interfaces, scan rate: $20 \mathrm{mV} / \mathrm{s}$. (c) Determination of the $\Delta_{\mathrm{o}}^{\mathrm{w}} \phi_{1 / 2}$ of $\mathrm{TMA}^{+}, \mathrm{TEA}^{+}$, and $\mathrm{TBA}^{+}$at the water|TFT interface. Scan rate: $10 \mathrm{mV} / \mathrm{s}$ for cells IV and $\mathrm{V}$ and $30 \mathrm{mV} / \mathrm{s}$ for cell VI.

determined using the cell III (Scheme 1), then, using the cell IV the $\Delta_{\mathrm{o}}^{\mathrm{w}} \phi_{1 / 2}$ of $\mathrm{TMA}^{+}$was calibrated, which was in turn used to determine the $\Delta_{\mathrm{o}}^{\mathrm{w}} \phi_{1 / 2}$ of $\mathrm{TBA}^{+}$using the cell $\mathrm{V}$, and finally the $\Delta_{\mathrm{o}}^{\mathrm{w}} \phi_{1 / 2}$ of $\mathrm{TBA}^{+}$ was used to calibrate the transfer of TEA ${ }^{+}$using the cell VI. 
Eq. (1) was used to estimate the standard potentials $\left(\Delta_{\mathrm{o}}^{\mathrm{w}} \phi_{1 / 2}\right)$ at the water|TFT interface from the half-wave potential values, $\Delta_{\mathrm{o}}^{\mathrm{w}} \phi_{1 / 2}$, obtained experimentally.

$\Delta_{\mathrm{o}}^{\mathrm{w}} \phi_{1 / 2}=\Delta_{\mathrm{o}}^{\mathrm{w}} \phi^{0}+\frac{R T}{2 z F} \operatorname{In}\left(\frac{D_{\mathrm{w}}}{D_{\mathrm{o}}}\right)+\frac{R T}{2 z F} \operatorname{In}\left(\frac{\gamma_{o}}{\gamma_{w}}\right)$

where $D_{\mathrm{w}}, D_{\mathrm{o}}$ and $\gamma_{\mathrm{w}}, \gamma_{\mathrm{o}}$ are the diffusion and activity coefficients for the aqueous and the organic phases, respectively. The ratio $D_{\mathrm{w}} / D_{\mathrm{o}}$ was estimated by using Walden's rule $\eta^{\mathrm{w}} D^{\mathrm{w}}=\eta^{\circ} D^{\mathrm{o}}$, with $\eta$ the viscosity. The viscosity of water and TFT is equal to $0.0091 \mathrm{P}$ and $0.00038 \mathrm{P}$ (at $25^{\circ} \mathrm{C}$ ), respectively, and the constant $\frac{R T}{2 z F} \ln \left(\frac{D w}{D o}\right)$ was calculated to be $\pm 41.3 \mathrm{mV}$ for univalent ions.

The activity coefficients were calculated by using the extended Debye-Hückel equation (Eq. (3)) [32], where $\mu$ is the ionic strength and $a$ is the ion size, which for the ions studied in this work can be assumed as $0.3 \mathrm{~nm}$ in the aqueous phase and $0.6 \mathrm{~nm}$ in the organic phase [32].

$\log \gamma_{i}=\frac{-A z_{i}^{2} \mu^{1 / 2}}{1+B a_{i} \mu^{1 / 2}}$

The constants $A$ and $B$ were estimated by using Eqs. (3) and (4) [34], respectively. The obtained values were $A=12.71 \mathrm{~L}^{1 / 2} \mathrm{~mol}^{-1 / 2}$ and $B=9.60 \mathrm{~mol}^{-1 / 2} \mathrm{~nm}^{-1}$ for TFT and $A=0.51 \mathrm{~L}^{1 / 2} \mathrm{~mol}^{-1 / 2}$ and $B=3.3 \mathrm{~mol}^{-1 / 2} \mathrm{~nm}^{-1}$ for water.

$A=\frac{1.8245 \times 10^{-6}}{(D T)^{3 / 2}}$

$B=\frac{502.904}{(D T)^{1 / 2}}$

Therefore, the constant $\frac{R T}{2 z F} \ln \left(\frac{\gamma_{0}}{\gamma_{w}}\right)$ was calculated to be $\pm 35.6 \mathrm{mV}$ for univalent ions.

Finally, the $\Delta_{\mathrm{o}}^{\mathrm{w}} \phi^{0}$ is related to the $\Delta G_{\mathrm{tr}}^{0, \mathrm{w} \rightarrow \mathrm{o}}$ through Eq. (5).

$\Delta G_{\mathrm{tr}}^{0, \mathrm{w} \rightarrow \mathrm{o}}=z \mathrm{~F} \Delta_{\mathrm{o}}^{\mathrm{w}} \phi^{0}$

The $\Delta_{\mathrm{o}}^{\mathrm{w}} \phi_{1 / 2}$ determined experimentally and the corrected $\Delta_{\mathrm{o}}^{\mathrm{w}} \phi^{0}$ and $\Delta G_{\mathrm{tr}}^{0, \mathrm{w} \rightarrow \mathrm{TFT}}$ are tabulated in Table 1 along with $\Delta G_{\mathrm{tr}}^{0, \mathrm{w} \rightarrow \mathrm{o}}$ reported for water|DCE and water|NB interfaces.

$\Delta G_{\mathrm{tr}}^{0, \mathrm{w} \rightarrow \mathrm{o}}$ obtained at the water|TFT interface are quite similar to those reported for the water|DCE interface, which in some extent validates the data obtained in this work, considering that the dielectric constant of TFT is only slightly smaller than that of DCE.

Fig. 2 shows the relationship between the $\Delta G_{\mathrm{tr}}^{0, \mathrm{w} \rightarrow \mathrm{o}}$ obtained at the water|TFT interface and those reported at the water|DCE and water|NB interfaces. In both cases linear $\Delta G_{\mathrm{tr}}^{0, \mathrm{w} \rightarrow 0}$ relationships were found, in agreement with previous works for similar solvents [32]. The slopes of the correlation curves are close to the unity in

Table 1

Experimental half wave potentials, corrected standard transfer potentials and standard Gibbs energies of the partition for ion transfer at the water|TFT interface. The standard transfer potentials were corrected by considering the contribution from $\frac{R T}{2 z F} \ln \left(\frac{D w}{D o}\right)$, estimated to be approximately $\pm 41.3 \mathrm{mV}$, and the $\frac{R T}{2 z F} \ln \left(\frac{\gamma_{0}}{\gamma \mathrm{w}}\right)$ contribution, estimated to be approximately $\pm 35.6 \mathrm{mV}$. Standard Gibbs energies of the partition reported at the water|DCE and water|NB interfaces.

\begin{tabular}{lccccr}
\hline Ion & $\Delta_{\mathrm{o}}^{\mathrm{w}} \phi_{1 / 2, \mathrm{w} \rightarrow \mathrm{TFT}}$ & $\Delta_{\mathrm{o}}^{\mathrm{w}} \phi^{0, \mathrm{w} \rightarrow \mathrm{TFT}}$ & $\Delta G_{\mathrm{tr}}^{0, \mathrm{w} \rightarrow \mathrm{TFT}}$ & \multicolumn{1}{c}{$\begin{array}{l}\Delta G_{\mathrm{tr}}^{0, \mathrm{w} \rightarrow \mathrm{DCE}} \\
{[\operatorname{Ref}]}\end{array}$} & \multicolumn{1}{c}{$\begin{array}{l}\Delta G_{\mathrm{tr}}^{0, \mathrm{w}} \rightarrow \mathrm{NB} \\
{[\text { Ref] }}\end{array}$} \\
\hline $\mathrm{TPAs}^{+}$ & -0.260 & -0.337 & -32.5 & $-32.6[2]$ & $-36.0[10]$ \\
$\mathrm{TPB}^{-}$ & 0.265 & 0.342 & -33.0 & $-32.6[2]$ & $-36.0[10]$ \\
$\mathrm{TMA}^{+}$ & 0.270 & 0.193 & 18.6 & $17.6[5]$ & $4.0[10]$ \\
$\mathrm{TEA}^{+}$ & 0.108 & 0.031 & 3.0 & $4.7[2]$ & $-6.4[12]$ \\
$\mathrm{TPropA}^{+}$ & -0.019 & -0.096 & -9.3 & $-8.8[2]$ & $-16.4[10]$ \\
$\mathrm{TBA}^{+}$ & -0.146 & -0.222 & -21.4 & $-19.3[7]$ & $-26.5[12]$ \\
\hline
\end{tabular}

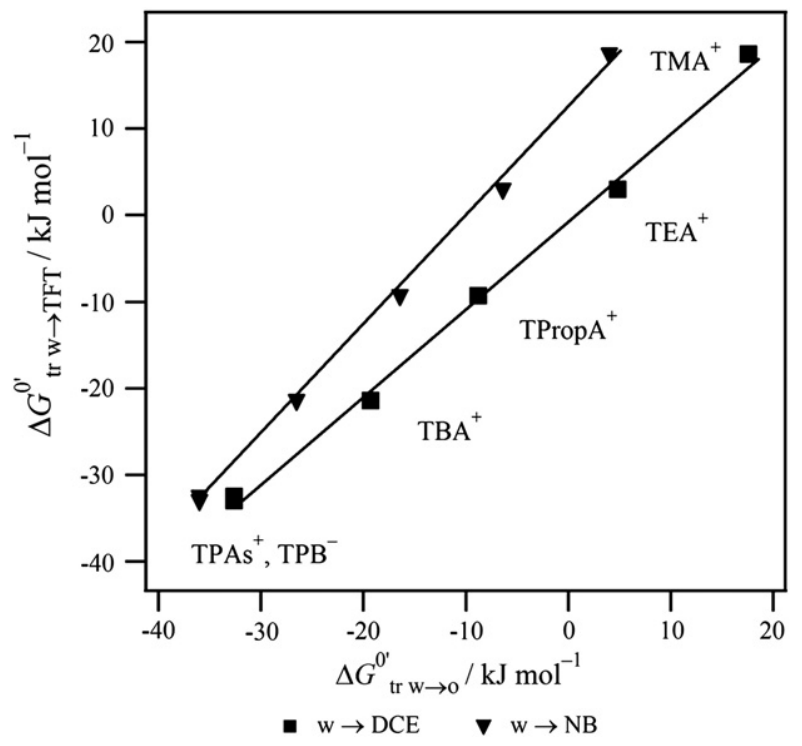

Fig. 2. Correlation between the $\Delta G_{\text {tr }}^{0}$ obtained at the water|TFT interface and those reported at the water|DCE $[2,5,7]$ and water|NB $[10,12]$ interfaces.

both cases; 1.0 and 1.3 when comparing with DCE and NB respectively, and the intercepts are -0.48 (TFT vs DCE) and 12.2 (TFT vs NB) indicating that the $\Delta G_{\mathrm{tr}}^{0, \mathrm{w} \rightarrow \text { TFT }}$ are larger than those reported for the transfer to NB. Those values also correlate rather well with those found by other authors for similar comparisons [32] and suggest that the $\Delta G_{\mathrm{tr}}^{0, \mathrm{w} \rightarrow \mathrm{o}}$ determined at the water|DCE and water|NB interfaces, could be used to estimate $\Delta G_{\mathrm{tr}}^{0, \mathrm{w}} \rightarrow \mathrm{o}$ at the water|TFT interface by using these empirical relationships [32].

\section{Conclusion}

TFT was found to be a good substitute for DCE and NB for studying charge transfer at liquid|liquid interfaces, with the advantage of having lower toxicity (TFT is not considered a carcinogen agent) and price and offering a larger potential window.

\section{Acknowledgements}

The authors thank the NCCR SNF MUST project and the EPFL for financial support.

\section{References}

[1] L. Zhong, M. Zhou, S. Gan, Y. Bao, X. Dong, L. Niu, L. Guo, Electrochemistry Communications 13 (2011) 221.

[2] M.H. Abraham, A.F. Danil de Namor, Journal of the Chemical Society, Faraday Transactions 1 (72) (1976) 955.

[3] N. Younan, M. Hojeij, L. Ribeaucourt, H.H. Girault, Electrochemistry Communications 12 (2010) 912.

[4] A. Trojánek, J. Langmaier, B. Su, H.H. Girault, Z. Samec, Electrochemistry Communications 11 (2009) 1940.

[5] J. Czapkiewicz, B. Czapkiewicz-Tutaj, Journal of the Chemical Society, Faraday Transactions 1 (76) (1980) 1663.

[6] S.E.C. Dale, P.R. Unwin, Electrochemistry Communications 10 (2008) 723.

[7] J.P. Antoine, I. de Aguirre, F. Janssens, F. Thyrion, Bulletin de la Societe Chimique de France 5-6 (1980) 207.

[8] A.J. Olaya, M.A. Méndez, F. Cortés-Salazar, H.H. Girault, Journal of Electroanalytical Chemistry 644 (2010) 60

[9] E. Bak, M. Donten, Z. Stojek, Electrochemistry Communications 10 (2008) 1074.

[10] A.F. Danil de Namor, T. Hill, Journal of the Chemical Society, Faraday Transactions 1 (79) (1983) 2713.

[11] F. Scholz, R. Gulaboski, K. Caban, Electrochemistry Communications 5 (2003) 929.

[12] T. Wandlowski, V. Marecek, Z. Samec, Electrochimica Acta 35 (1990) 1173.

[13] R.E. Yodaiken, J.R. Babcock, Archives of Environmental Health 26 (1973) 281.

[14] T. Nouchi, H. Miura, M. Kanayama, O. Mizuguchi, T. Takano, International Archives of Occupational and Environmental Health 54 (1984) 111.

[15] J.-R. Liu, S. Fang, M.-P. Ding, Z.-C. Chen, J.-J. Zhou, F. Sun, B. Jiang, J. Huang, Journal of the Neurological Sciences 292 (2010) 111. 
[16] W.E. Luttrell, E. Rukundo, Journal of Chemical Heath and Safety 17 (2010) 24

[17] Y. Ohkuma, S. Kawanishi, Biochemical and Biophysical Research Communications 257 (1999) 555.

[18] R.C. Cattley, J.I. Everitt, E. Gross, O.R. Moss, T.E. Hamm, J.A. Popp, Fundamental and Applied Toxicology 25 (1995) 159.

[19] G. Luo, S. Malkova, S.V. Pingali, D.G. Schultz, B. Lin, M. Meron, T.J. Graber, J. Gebhardt, P. Vanysek, M.L. Schlossman, Electrochemistry Communications 7 (2005) 627.

[20] Y. Cheng, D. Schiffrin, Journal of Electroanalytical Chemistry 409 (1996) 9.

[21] A.M. O'Mahony, M.I.D. Scanlon, A. Berduque, V. Beni, D.W.M. Arrigan, E. Faggi, A. Bencini, Electrochemistry Communications 7 (2005) 976.

[22] H. Katano, H. Tatsumi, M. Senda, Talanta 63 (2004) 185.

[23] T. Solomon, H. Alemu, B. Hundhammer, Journal of Electroanalytical Chemistry 169 (1984) 303.

[24] B. Hundhammer, C. Müller, T. Solomon, H. Alemu, H. Hassen, Journal of Electroanalytical Chemistry 319 (1991) 125.
[25] Y. Yasui, Y. Kitazumi, H. Mizunuma, N. Nishi, T. Kakiuchi, Electrochemistry Communications 12 (2010) 1479.

[26] D.S. Silvester, D.W.M. Arrigan, Electrochemistry Communications 13 (2011) 477

27] N. Nishi, S. Imakura, T. Kakiuchi, Analytical Chemistry 78 (2006) 2726.

[28] Z. Samec, J. Langmaier, T. Kakiuchi, Pure and Applied Chemistry 81 (2009) 1473

[29] T.J. Stockmann, J. Zhang, J.C. Wren, Z. Ding, Electrochimica Acta 62 (2012) 8

[30] A. Ogawa, D.P. Curran, The Journal of Organic Chemistry 62 (1997) 450.

[31] R.E. Banks, B.E. Smart, J.C. Tatlow, Organic Fluorine Chemistry, Principles and Applications, , Plenum, New York, 1994.

[32] S. Wilke, T. Zerihun, Journal of Electroanalytical Chemistry 515 (2001) 52.

[33] V.J. Cunnane, D.J. Schiffrin, M. Fleischmann, G. Geblewicz, D. Williams, Journal of Electroanalytical Chemistry 243 (1988) 455.

[34] B. Matuszewska, T. Hilczer, Pramana 23 (1984) 47. 